\title{
Effect of Lamaze method on pain perception, anxiety, fatigue and labour outcome among primi mothers during labour process
}

Kuruvilla S*

*Corresponding author:

Dr. Sindhu Kuruvilla, Phd (N), Professor.

Little Flower College of Nursing, Trivandrum, Kerala, India

Email: sindhulfcnprincipal@gmail.com ORCID

Information about the article:

Received: Jan. 17, 2019

Accepted: Feb. 20, 2019

Published online: Dec. 27, 2019

\section{Publisher}

Nepal Health Research Society, Bahundhara -6, Gokarnesowor Municipality, Kathmandu, Nepal

eISSN 2382-5545, ISSN 2676-1343 (Print)

(C) The Author(s). 2019

Content licensing: CC BY 4.0

\begin{abstract}
\section{Background}

Labour pain is the most severe pain a woman might ever experience in her life. Severity of pain and duration of labour psychologically affects a mother. It may lower the confidence, self-esteem and increase the level of anxiety and fatigue. The main purpose of the study was to evaluate the effectiveness of video based Lamaze Nursing care intervention on pain perception, anxiety, fatigue and labour outcome among Primigravida women admitted during childbirth. The conceptual framework for the study was developed based on Ernestine Wiedenbach's helping art of clinical nursing theory.
\end{abstract}

\section{Materials and methods}

Quantitative Post-test only control group design was used. The sample size was 200 primigravida mothers, 37 to 40 weeks of gestation (100 in each group) and the study was conducted in first stage of labour room cosmopolitan hospital, Trivandrum.

\section{Results}

The study findings shows that Lamaze method and the techniques used in it were effective in reducing the pain, anxiety and fatigue during child birth and leads to a fine labour outcome Pain perception in experimental group was less when compared to control group, $\mathrm{t}=4.11(.01)$, anxiety in experimental group was lower when compared to control group, $\mathrm{t}$ value $=6.44(.01)$, Fatigue was less among the experimental group when compared to control group, $t$ value $=9.09(.00)$ was significant. It was inferred that labour outcome in experimental group was better when compared to control group. $\mathrm{t}=5.17$ significant at 0.01 level. It was also depicted that there was association between pain perception, anxiety and fatigue and selected demographic variable like age ,education duration of marital life ,onset of labour

\section{Conclusion}

The findings of this study indicated that Lamaze nursing care intervention helped the women to cope up with the birthing process. It is a simple, easy to implement and most acceptable way to tackle pain, anxiety and fatigue among parturient mothers. Nurses and childbirth educators must be willing to provide comprehensive childbirth education that introduces women to a variety of pain management options. The excavator results supported that the incorporation of Lamaze method in nursing care is one of the best intervention to cope up with labour process.

\section{Keywords}

Lamaze method, fatigue and labour outcome, pain perception, anxiety, 